\title{
EXPERIMENTAL AND THEORETICAL STUDIES ON BEARING CAPACITY OF CONICAL SHELL FOUNDATIONS COMPOSED OF REACTIVE POWDER CONCRETE
}

\author{
Mohammed Y. FATTAH ${ }^{1) *}$, Waleed A. WARYOSH ${ }^{2)}$ and Mohammed A. E. AL-HAMDANI ${ }^{3)}$ \\ ${ }^{1)}$ Building and Construction Engineering Department, University of Technology, Baghdad, Iraq \\ ${ }^{2)}$ Civil Engineering Department, College of Engineering, Al-Mustansiriyah University, Baghdad, Iraq \\ ${ }^{3)}$ Building and Construction Engineering Department, University of Technology, Baghdad, Iraq \\ *Corresponding author's e-mail: myf_1968@yahoo.com
}

\begin{tabular}{l} 
ARTICLE INFO \\
\hline Article history: \\
Received 11 February 2015 \\
Accepted 8 July 2015 \\
Available online 27 August 2015 \\
\hline
\end{tabular}

Keywords:

Reactive powder concrete

Shell foundation

Silica fume

Steel fiber

Bearing capacity

\begin{abstract}
Many forms of shells are available for use as foundations. Then frustum of a cone in the upright position can serve as footing for columns or raft for structure such as chimneys. Reactive Powder Concrete (RPC) is an ultra-high strength, low porosity material with high cement and silica fume contents and steel fibers.

The present study aims at studying the RPC as a material used to construct RPC shell foundations. A complete load-frame assembly was designed and fabricated for experimental work. Experimental tests are conducted to study the effect of steel fiber volumetric ratio $\left(\mathrm{V}_{\mathrm{f}}\right)$, silica fume content $\left(\mathrm{S}_{\mathrm{f}}\right)$, change eccentricity, and rise of shell to radius of base ratio $\left(\mathrm{f} / \mathrm{r}_{2}\right)$ on the behavior of conical shell foundations.

Results of tests conducted on wire - reinforced small - concrete models of conical foundations under loads established substantially high values of load factors involved in the traditional design of the conical foundations by membrane theory. The increased ratio of height to radius ( $\left.\mathrm{f} / \mathrm{r}_{2}\right)$ for the shell foundation from 0.25 to 0.75 increases the ultimate load of footing by about $15 \%$. The conical shell footing can admirably resist smaller values of accidental eccentricities of load (due to unanticipated moment) that may occur in practice.
\end{abstract}

\section{INTRODUCTION}

Shell foundations present an economical alternative solution to the conventional plane foundations in case of heavy loads to be transmitted to low-bearing capacity soil. The economical advantage of this type of foundations becomes more obvious in countries of high material cost to labor cost. This latter property, which represents a benchmark for developing countries, in addition to the fact of presence of low-bearing capacity soils in different parts of the world.

Shell foundations reveal high bearing capacity values which make them suitable in soft or weak soils. At the same time, these foundations are thin which makes the failure in concrete preceding the soil failure. Therefore, it is intended to improve concrete quality to increase its load carrying capacity and develop the shell foundation behavior to be close to conventional foundations.

Even though a variety of shells lend themselves for adoption in roofs, those that can be adopted for use in foundations are far too few. The following is an account of some of the more common types of shells used in foundations (Kurian, 2006): hyperbolic paraboloidal shells, conical shells, inverted dome, elliptic paraboloid, cylindrical shells, pyramidal sell, spherical shells, and triangular shell footing for load bearing wall.

Sharma and Mawal (1971) presented a membrane solution to symmetric and anti - symmetric loading for inverted annular spherical shell foundations. It was found that the effect of linear anti-symmetrical soil reaction increases the meridian stresses by $16 \%$ of the stresses caused by symmetrical loading, while in the case of hoop stresses, this percentage is only $13 \%$. Therefore, they deduced that the contribution due to anti-symmetrical loading can be very well taken into account by increasing the stresses obtained due to symmetrical loading by $33.125 \%$ as suggested in Indian Standard Code of Practice (1980). Consequently, the analysis due to anti-symmetrical loading may be completely avoided.

Ramaswamy and Rafik (1972) described the details of experimental tests carried out on a model of hyperbolic paraboloid footing. The test on the model was undertaken with the object of assessing the margin of safety that such footing possesses against failure. Such tests were also useful to study the manner in which failure would be initiated under overloads in excess of the design loads. By assuming a bearing capacity of the soil to be $46 \mathrm{kN} / \mathrm{m}^{2}$, a model of hypar footing $1.37 \mathrm{~m} \times 1.37 \mathrm{~m}$ designed for a load of $98.1 \mathrm{kN}$ was tested. The load was applied by using a hydraulic jack of 200 ton $(1961 \mathrm{kN})$ capacity placed on the column. The jack reacted on two loading beams which were $2-$ I sections $10^{\prime \prime} \times 5^{\prime \prime}$ at the center of their spans. The beams were anchored down to two $0.4 \mathrm{~m}$ diameter Franki piles by $16 \mathrm{~mm}$ diameter bars. Seven dial gauges were positioned on the shell and the edge members. The observations of the dial gauges were 
recorded up to a load of $333.6 \mathrm{kN}$. Thereafter, the dial gauges were removed but the loading was continued up to $369.2 \mathrm{kN}$. Further loading was not possible, not because of failure in the foundation, but because the supporting (or reacting) beams began to buckle and the test had to be discontinued.

The following conclusions were drawn:

1. The load of $369.2 \mathrm{kN}$, at which buckling of the supporting beams took place, offers a margin of safety of 3.75 against the design load.

2. The reading of the dial gauges showed that the footing behaved as a rigid structure.

3. There was no danger of sudden brittle failure because failure of the footing would be initiated in the first instance by the yielding of the steel in the edge beams.

4. From the experience gained from this test, it was reasonable to conclude that such footings could be confidently used to transfer high - column loads to soils of poor bearing capacity.

Indian Standards IS (1980) and Kurian (1982) stated that, if the horizontal plane passing through the base of a shell footings is considered to correspond to the same plane under a flat footing, there will be a little difference between the soil design of shell and plane footings except that the core soil inside or underneath the shell footing would enter into calculations for the allowable bearing pressure. It should be appreciated that this approach is sufficiently sound so long as the core soil can be assumed to behave integrally with the footing. An interesting side effect of this is that, there is a greater friction available between the core soil and the foundation soil in the case of shell footings than between the concrete and foundation soil in the case of plane footings, to resist horizontal loads.

Huat and Mohammed (2006) using the finite element code, PLAXIS, carried out a study on the geotechnical behavior of the shell footings. From the finite element results, it was found that the shell footing had a better load carrying capacity compared with the slab/flat footing for a similar cross sectional area. The FE analysis also showed a reasonably good agreement with the laboratory experimental results; with a discrepancy of within 11 to $25 \%$. The effect of adding edge beams at the bottom of the shell footings was studied numerically and found to be beneficial in increasing the load carrying capacity of the footing. Fully embedded shell footing was shown to have a better load carrying capacity compared with the footing with no embedment.

Esmaili and Hataf (2008) determined the ultimate load capacities of conical and pyramidal shell foundations on unreinforced and reinforced sand by laboratory model tests and numerical analysis. The results were compared with those for circular and square flat foundations. Eight foundation models on unreinforced and reinforced sand were tested in which the influence of shell configuration on ultimate load capacity was investigated. Both the experimental and numerical studies indicated that, if shell foundation thickness increases, the behavior of the shell foundation on either reinforced sand or unreinforced sand gets closer to that of flat foundations. A new factor was also defined to present a unique relation between the ultimate load capacity of shell and flat foundations.

Two types of shell foundations were used in the investigation, namely, conical and pyramidal shells to represent the axisymetric and three-dimensional conditions, respectively. To examine the effect of the shell thickness on the ultimate load capacity, three types of conical and pyramidal model shell foundations have been made and tested.

The objective of this study is to present a better understanding of the behavior of shell foundations and assess the margin of safety that such footing possesses against failure, in addition to investigate the parameters affecting their behavior. Small scale models of shell foundations embedded in sandy soils are prepared; the shells in this study are prepared from RPC mixed with different percentages of silika fume. This is the first time, the shells are constructed from RPC. Theoretical equations were used to validate the method of improvement of the concrete of the shell foundation making use of the development of these equations.

\section{EXPERIMENTAL WORK}

The term reactive powder concrete, RPC, has been used to describe a fiber-reinforced, super plasticized, silica fume-cement mixture with very low water/cement ratio $(\mathrm{w} / \mathrm{c})$ characterized by the presence of very fine sand instead of ordinary aggregate. In the present research work, these components are used to cast foundation models as well as control specimens.

\section{MATERIALS}

Ordinary Portland cement (type I) was used. The chemical and physical properties are listed in Tables 1 and 2, respectively. Fine natural sand was used, its grading is shown in Table 3 compared with British Standard B.S. 882:1992. The sand has a specific gravity of 2.7 and sulphate content of $0.21 \%$.

A grey dandified grade $920 \mathrm{D}$ silica fume (which is a byproduct from the manufacture of silicon or ferro-silicon metal) was used. Silica fume is an extremely powder, its fine powder particles are hundreds of times smaller than cement particles, always used in small percentage even as partial replacement of cement or as an additive to enhance concrete properties.

The benefits that result from adding silica fume are related to changes in the microstructure of concrete. These changes result from two different but equally important processes (Silica Fume, User's Manual, 2005):

A. Physical contribution; Adding silica fume brings millions and millions of very small particles to a concrete mixture, it fills in the spaces between 
Table 1 Chemical composition and main components of ordinary Portland cement.

\begin{tabular}{lr}
\hline \multicolumn{1}{c}{ Oxides composition } & Content \% \\
\hline $\mathrm{CaO}$ & 61.21 \\
$\mathrm{SiO}_{2}$ & 21.80 \\
$\mathrm{Al}_{2} \mathrm{O}_{3}$ & 5.10 \\
$\mathrm{Fe}_{2} \mathrm{O}_{3}$ & 2.80 \\
$\mathrm{MgO}_{\mathrm{SO} 3}$ & 2.11 \\
$\mathrm{~L} . \mathrm{O} . \mathrm{I}$. & 1.09 \\
Insoluble residue & 3.51 \\
Lime Saturation Factor, & 0.98 \\
L.S.F. & 0.84 \\
\hline \multicolumn{2}{c}{ Main compounds } \\
$\mathrm{C}_{3} \mathrm{~S}$ & \\
$\mathrm{C}_{2} \mathrm{~S}$ & 42.06 \\
$\mathrm{C}_{3} \mathrm{~A}$ & 31.02 \\
$\mathrm{C}_{4} \mathrm{AF}$ & 8.78 \\
\hline
\end{tabular}

cement grains. This phenomenon is frequently referred to as particle packing or micro-filling. Even if silica fume does not react chemically, the micro-filler effect would bring about significant improvements in the nature of concrete.

B. Chemical contribution; Because of its very high amorphous silicon dioxide content, silica fume is a very reactive pozzolanic material in concrete. As the Portland cement in concrete begins to react chemically, it releases calcium hydroxide. The silica fume reacts with this calcium hydroxide to form additional binder material (calcium silicate hydrate $(\mathrm{C}-\mathrm{S}-\mathrm{H}))$ which is very similar to the calcium silicate hydrate formed from the Portland cement.

Chemical composition of silica fume used in this investigation is investigated as shown in Table 4.

The superplasticizer used was a modified polycarboxylates based polymer manufactured and supplied by SIKA $^{\circledR}$ under the commercial name Sika ${ }^{\circledR}$ Viscocrete $^{\circledR} 3110$ which is a high performance high range water reducing agent plus stabilizing agent. Stabilizing agent can be defined as an admixture added to fresh concrete to increase cohesion and segregation resistance. Table 5 shows the technical
Table 2 Physical properties of cement.

\begin{tabular}{lc}
\hline \multicolumn{1}{c}{ Physical Properties } & $\begin{array}{c}\text { Test } \\
\text { results }\end{array}$ \\
\hline Specific surface area (Blaine method), & 483 \\
$\mathrm{~m} / \mathrm{kg}$ & \\
\hline Setting time (Vicat apparatus), & $2: 45$ \\
Initial setting, hr:min & $4: 45$ \\
Final setting, hr:min & \\
\hline Compressive strength, MPa & 31.30 \\
3 days & 41.00 \\
7 days & 0.35 \\
\hline Soundness (Autoclave method), \%
\end{tabular}

Table 3 Grading of fine sand compared with requirements of B.S. 882:1992.

\begin{tabular}{ccc}
\hline $\begin{array}{c}\text { Sieve } \\
\text { size } \\
(\mathrm{mm})\end{array}$ & $\begin{array}{c}\text { Cumulative } \\
\text { passing } \%\end{array}$ & $\begin{array}{c}\text { Cumulative passing \% } \\
\text { (limits of B.S. 882:1992 } \\
\text { Fine aggregate grading) }\end{array}$ \\
\hline 5.00 & 100 & 100 \\
2.36 & 100 & $80-100$ \\
1.18 & 100 & $70-100$ \\
0.60 & 93.3 & $55-100$ \\
0.30 & 42 & $5-70$ \\
0.15 & 0 & $0-15$ \\
\hline
\end{tabular}

Table 4 Chemical analysis of silica fume.

\begin{tabular}{cc}
\hline Oxide composition & Oxide content \% \\
\hline $\mathrm{SiO}_{2}$ & 86.46 \\
$\mathrm{Al}_{2} \mathrm{O}_{3}$ & 1.60 \\
$\mathrm{Fe}_{2} \mathrm{O}_{3}$ & 1.11 \\
$\mathrm{Na}_{2} \mathrm{O}$ & 0.30 \\
$\mathrm{~K}_{2} \mathrm{O}$ & 1.90 \\
$\mathrm{CaO}$ & 1.80 \\
$\mathrm{MgO}$ & 1.90 \\
$\mathrm{SO}_{3}$ & 0.25 \\
$\mathrm{~L}_{3} \mathrm{O}^{*}$ & 4.02 \\
\hline
\end{tabular}

* Loss on Ignition.

Table 5 Technical description of Sika Viscocrete 3110 (Sika Gulf B.S.S.C, 2006).

$\begin{array}{cc}\text { Chemical Base } & \text { Aqueous solution of modified Polycarboxylate co-polymers } \\ \text { Appearance / colors } & \begin{array}{c}\text { Clear colorless to yellowish liquid } \\ \text { Approximately } 1.085 \mathrm{~kg} / \mathrm{m}^{3}\end{array} \\ \text { Density } & 150 \mathrm{mpc} @ 20 \mathrm{c}^{\circ} \\ \text { Viscosity } & 4.3 \\ \text { pH value } & 0.4-1.5 \% \text { by weight of binder } \\ \text { Dosage } & \begin{array}{c}\text { Dry condition at temp } 5^{\circ} \mathrm{C} \text { to } 35^{\circ} \mathrm{C} / \\ \text { Storage Condition / } \\ \text { Shelf Life }\end{array} \\ \end{array}$


Table 6 Properties of the steel fibers.

\begin{tabular}{ll}
\hline Description & straight \\
Length & $13 \mathrm{~mm}$ \\
Diameter & $0.2 \mathrm{~mm}$ \\
Density & $7800 \mathrm{~kg} / \mathrm{m}^{3}$ \\
Tensile & $2600 \mathrm{MPa}$ \\
Strength & \\
Aspect & $1 / \mathrm{d}=65$ \\
Ratio & \\
\hline
\end{tabular}

Table 7 Properties of mixing with RPC.

\begin{tabular}{cccccccc}
\hline $\begin{array}{c}\text { Specimens } \\
\text { Designation }\end{array}$ & $\begin{array}{c}\text { Cement } \\
\mathrm{kg} / \mathrm{m}^{3}\end{array}$ & $\begin{array}{c}\text { Sand } \\
\mathrm{kg} / \mathrm{m}^{3}\end{array}$ & $\begin{array}{c}\text { Silica } \\
\text { fume } \\
\%^{*}\end{array}$ & $\mathrm{w} / \mathrm{c}$ & $\begin{array}{c}\text { Sika } \\
3110 \% \%^{* *}\end{array}$ & $\begin{array}{r}\text { Steel } \\
\text { fiber } \\
\mathrm{V}_{\mathrm{f}} \%{ }^{* * *}\end{array}$ & $\begin{array}{c}\text { Compressive } \\
\text { Strength } \\
\mathrm{f}^{\prime} \mathrm{c}^{\prime}(\mathrm{MPa})\end{array}$ \\
\hline M0.0-20 & 1000 & 1000 & 20 & 0.2 & 1.7 & 0.0 & 108 \\
M0.5-20 & 1000 & 1000 & 20 & 0.2 & 1.7 & 0.5 & 110.4 \\
M1.0-20 & 1000 & 1000 & 20 & 0.2 & 1.7 & 1.0 & 125 \\
M1.5-20 & 1000 & 1000 & 20 & 0.2 & 1.7 & 1.5 & 130.3 \\
M2.0-20 & 1000 & 1000 & 20 & 0.2 & 1.7 & 2.0 & 140 \\
M2.0-15 & 1000 & 1000 & 15 & 0.2 & 1.7 & 2.0 & 129.9 \\
M2.0-10 & 1000 & 1000 & 10 & 0.2 & 1.7 & 2.0 & 126.3 \\
\hline
\end{tabular}

* Percent of cement weight** Percent of binder (cement + silica fume) weight.

*** Percent of mix volume.

Table 8 Properties of the steel bars in tension.

\begin{tabular}{ccccccc}
\hline $\begin{array}{c}\text { Nominal } \\
\text { diameter } \\
(\mathrm{mm})\end{array}$ & $\begin{array}{c}\text { Actual } \\
\text { diameter } \\
(\mathrm{mm})\end{array}$ & $\begin{array}{c}\text { Yield s } \\
(\mathrm{MPa})\end{array}$ & $\begin{array}{c}\text { Yield } \\
\text { strength } \\
(\mathrm{mm} / \mathrm{mm})\end{array}$ & $\begin{array}{c}\text { Ultimate tensile } \\
\text { strength }(\mathrm{MPa})\end{array}$ & $\begin{array}{c}\text { Ultimate } \\
\text { strain } \\
(\mathrm{mm} / \mathrm{mm})\end{array}$ & $\begin{array}{c}\text { Modulus of } \\
\text { elasticity (MPa) }\end{array}$ \\
\hline 2 & 3.14 & 310 & 0.00157 & 420 & 0.175 & 197000 \\
\hline
\end{tabular}

description of Sika ${ }^{\circledR}$ Viscocrete ${ }^{\circledR} 3110$. The sulphonic groups of the polymer chains increase the negative charge on the surface of the cement particles and dispersion of the cement occurs by electrostatic repulsion.

RPC contains small steel fibers rather than large aggregates. Each steel fiber has a diameter about $175 \mu \mathrm{m}$ and length of approximately $13 \mathrm{~mm}$.

The steel fibers used in this testing program are straight steel fibers manufactured by Bekaert Corporation. The fibers have the properties described in Table 6. A thin brass coating is applied to the fibers during the drawing process. This coating disappears during the mixing process and is no longer clearly visible during the casting of the steel fibers mixes.

\section{CONCRETE MIX DESIGN}

In the most basic form, reactive powder concrete contains high content of Portland cement as main cementations material, beside silica fume as a second supplementary cementations' component. Both sand to cement ratio $(\mathrm{s} / \mathrm{c})$ and water cement ratio $(\mathrm{w} / \mathrm{c})$ are low. The super plasticizer has been used in an appropriate ratio to give flowable concrete. Within the above limits and according to pervious researches (Philippot et al., 1996 and Saderkarimi, 2004), many mix proportions are tried in this investigation to get maximum compressive strength and flow of $95 \%$ according to ASTM C109 and ASTM C1437.

The properties of the micro concrete used for casting the models are shown in Table 7. The letter M denotes specimens; the first number indicates the percentage of fiber content $\left(\mathrm{V}_{\mathrm{f}}\right)$ and the second number indicates the percentage of silica fume $\left(S_{f}\right)$.

\section{MIXING PROCEDURE}

Initially, a small trial batch mixing was done in a small rotary mixer of $0.25 \mathrm{~m}^{3}$ capacity. The mixing sequence was as follows: the desired quantity of silica fume was mixed in dry state with the required quantity of cement. This operation was continued for 5 minutes to ensure that silica fume powder was thoroughly dispersed between cement particles. Then, fine sand was loaded into the mixer and mixed for 5 minutes. Then, the super plasticizer was dissolved in water and the solution of water and super plasticizer was added to the rotary mixer and the whole mix ingredients were mixed for a sufficient time. The mixer was stopped and mixing was continued manually especially for the portions not reached by the blades of the mixer. The mixer was then operated for 5 minutes to attain reasonable fluidity. Fibers were uniformly distributed into the mix slowly in 2 minutes during mixing process. In total, the mixing of one batch requires approximately 17-18 minutes.

Several effects were noticed when adding the fibers to the concrete matrix, the great reduction in workability which is reduced as the fiber content is increased which was noticed during mix procedure. These results were also noticed by other investigators (ASTM C230-14, ASTM C39-05, and Philippot et al., 1996).

\section{STEEL WIRE}

The material of reinforcement was mild steel wires of $2 \mathrm{~mm}$ diameter, taken from one lot. The tension tests of bars and minerals gave the properties listed in Table 8 with all values shown being the average of three specimens for each bar diameter. The results of testing this bar meet the ASTM A615/615M-05a requirements. 
Table 9 Properties of hardened RPC.

\begin{tabular}{ccccccc}
\hline $\begin{array}{c}\text { Specimens } \\
\text { Designation }\end{array}$ & $\begin{array}{c}\mathrm{V}_{\mathrm{f}} \\
\%\end{array}$ & $\begin{array}{c}\text { Silica } \\
\text { Fume } \\
\%\end{array}$ & $\begin{array}{c}\text { Compressive } \\
\text { Strength f'c } \\
(\mathrm{MPa})\end{array}$ & $\begin{array}{c}\text { Splitting Tensile } \\
\text { Strength f'sp } \\
(\mathrm{MPa})\end{array}$ & $\begin{array}{c}\text { Modulus of } \\
\text { Rupture f'r } \\
(\mathrm{MPa})\end{array}$ & $\begin{array}{c}\text { Modulus of } \\
\text { Elasticity Ec } \\
(\mathrm{GPa})\end{array}$ \\
\hline M 0.0-20 & 0.0 & 20 & 108 & 12 & 9.1 & 40.00 \\
M 0.5-20 & 0.5 & 20 & 110.4 & 13 & 15 & 44.40 \\
M 1.0-20 & 1.0 & 20 & 125 & 14 & 15.8 & 45.00 \\
M 1.5-20 & 1.5 & 20 & 130.3 & 18 & 21.5 & 50.00 \\
M 2.0-20 & 2.0 & 20 & 140 & 21 & 22 & 52.30 \\
M 2.0-15 & 2.0 & 15 & 129.9 & 16.5 & 17.5 & 51.30 \\
M 2.0-10 & 2.0 & 10 & 126.3 & 15 & 16.9 & 46.67 \\
\hline
\end{tabular}

\section{DETERMINATION OF THE CONSISTENCY OF CONCRETE MIXTURES}

The consistency was tested by the flow table test in accordance with ASTM C1437-01. The flow is the resulting increase in average base diameter of the mortar mass, expressed as a percentage of the original base diameter of the test cone, i.e.:

$$
\text { flow }=\frac{D-100}{100} \times 100 \%
$$

where:

$D$ : Average diameter of the spread concrete (mm) measured in four directions.

\section{TESTING OF SPECIMENS}

A series of tests are conducted to determine the compressive strength, modulus of rupture, splitting tensile strength and modulus of elasticity of RPC at the age of 28 days. Table 9 shows the average test results.

\section{FOUNDATION DETAILS}

In this paper, thirty eight models of (prototype) conical shell foundations are tested with and without ring beam with reactive powder cement and normal concrete to study the effect of reactive powder cement on the behavior of shell foundations.

The conical shell foundations were casted in steel frame which consists of three pieces, all the pieces are connected together by steel bolts. The shallow shell foundations details are presented in Figure 1 and Table 10

\section{CONICAL FOOTING WITH DIFFERENT VOLUME FRACTIONS OF FIBERS $\left(V_{f}\right)$}

Five values of steel fiber volume fractions of 0 , $0.5 \%, 1.0 \%, 1.5 \%$, and $2.0 \%$ were used in casting the shells, in order to study the effect of steel fiber content on the shear strength. Taking into consideration the aspect ratio of the fibers used and the type of concrete mix, a maximum of $2.0 \%$ fiber content was used in which the fibers were found to achieve a practical and uniform distribution within the fresh and hardened concrete. If greater than this percentage was used, mixing problems would rise as a result of the substantial immediate loss of workability of the mix and non - uniform distribution of fibers due to the effect of fiber balling so that great efforts and relatively long vibration time would be required in manufacturing the test shells.

\section{CONICAL FOOTING WITH DIFFERENT SILICA FUME PERCENTAGES ( $\left.S_{f}\right)$}

Three percentages of silica fume $\left(S_{f}\right)$ were used to obtain different grades of concrete to study the effect of concrete compressive strength on the shear strength. The percentage of silica fume was $5 \%, 10 \%$ and $15 \%$ by mass of cementations materials.

\section{CONICAL FOOTING WITH CHANGE OF ( $\left.f / r_{2}\right)$}

Three models were used in casting the shells to study the effect of rise to radius of shell. The models were designed for a considered change in shell conical footing, giving the ratio $\left(f / r_{2}\right) 0.25,0.5$, and 0.75 , respectively.

\section{PREPARATION OF SAND BED}

Dry sand is chosen to be the bed for testing the models. One of the factors which determinates the ability of the bed of sand to carry a foundation without undue settlement is the density of packing grains. When an experiment with small model foundation is to be made, the scale of work demands a better uniformity of density throughout the bed that cannot usually be found in nature. The scale of the work adopted in the experiments will satisfy the need to reproduce the same experimental conditions. Therefore, the experiments require a method of forming artificial bed of sand that is homogeneous.

The mechanical or sieve analysis is performed to determine the distribution of the coarser, larger-sized particles, and the hydrometer method is used to determine the distribution of the finer particles according to ASTM D2487 - 2000. The sand is classified as poorly graded sand, SP, according to the Unified Soil Classification System as given in Table 11.

The density of the soil was controlled by raining. Experimentally, a wide range of density in dry sand 


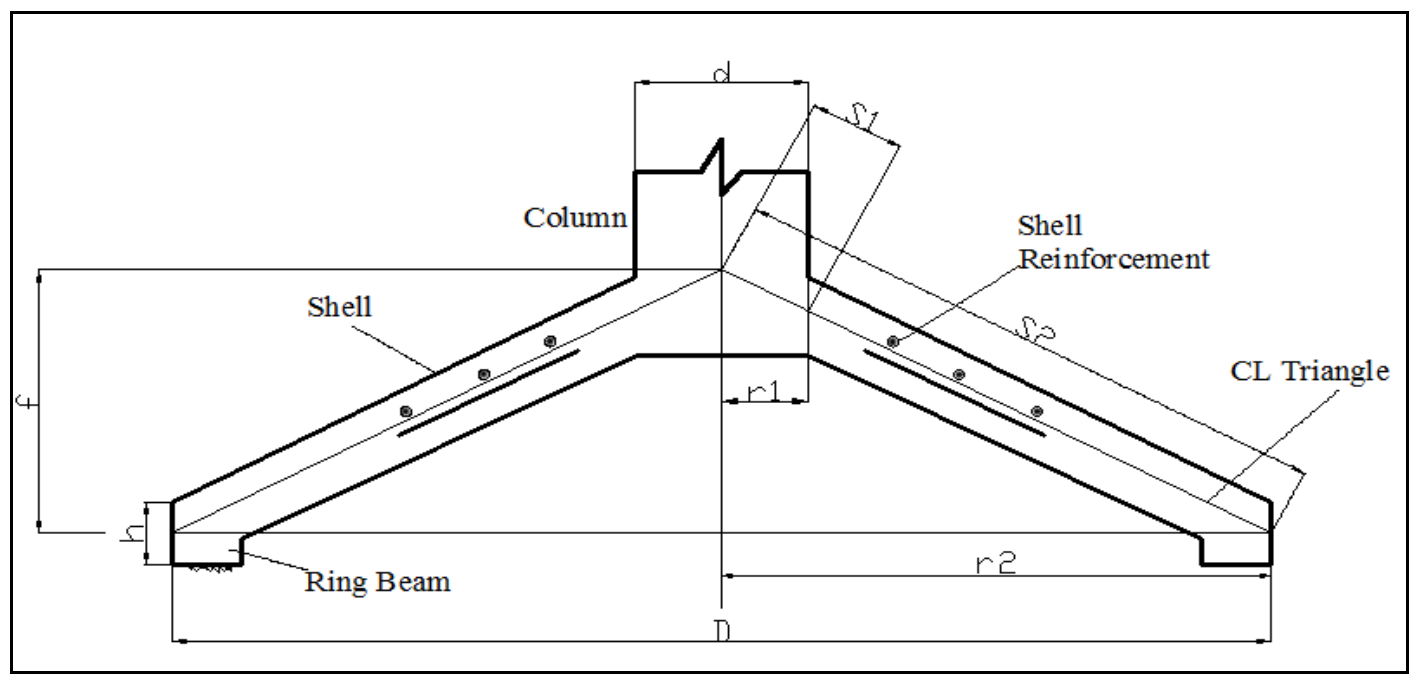

$\mathrm{D}($ diameter $)=400 \mathrm{~mm} . \quad \mathrm{d}=80 \mathrm{~mm}$

$\begin{array}{lll}\mathrm{h}(\text { thickness })=10 \mathrm{~mm} . & \mathrm{r} 1=40 \mathrm{~mm} & 1 \mathrm{~mm}=0.03936996 \mathrm{in} . \\ \mathrm{S}_{1}=35 \mathrm{~mm} & \mathrm{r} 2=200 \mathrm{~mm} & \end{array}$

8 rods

No. of rods radial steel rods $(\phi 2 \mathrm{~mm})$

2 rods@20 mm spacing.

No. of rods hoop steel (beginning from the edge) $(\phi 2 \mathrm{~mm})$

6 rods@30 mm spacing.

No. of rods ring beam rods $(\phi 2 \mathrm{~mm})$

4 rods

a. General details.

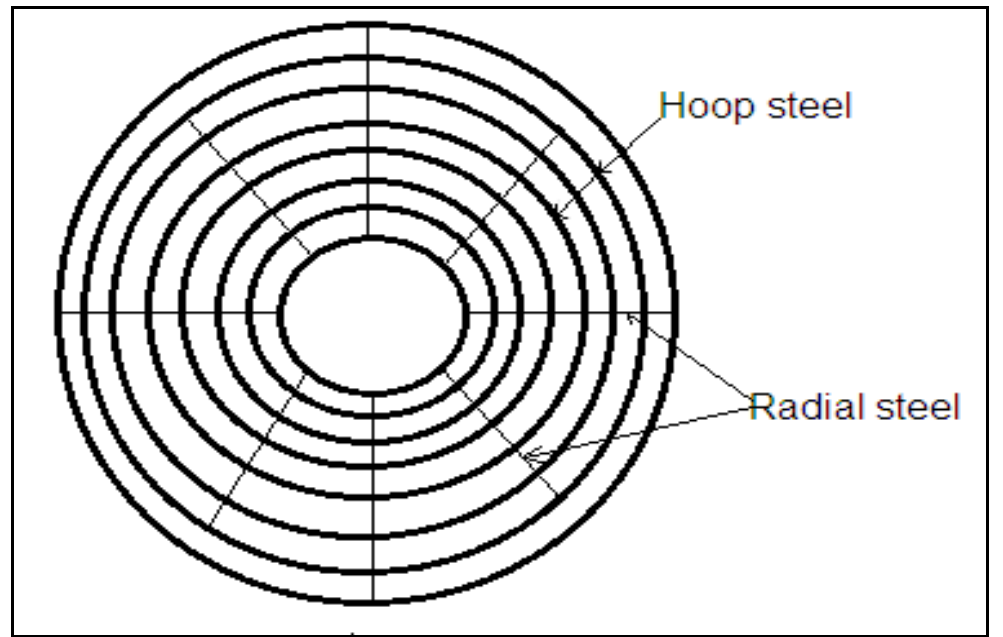

b. Typical reinforcement details for conical shell models.

Fig. 1 Conical shell footings. 
Table 10 Details of experimental work.

10a RPC shallow conical footing with ring beam.

\begin{tabular}{cccll}
\hline Group No. & Model No. & $\mathbf{f} / \mathbf{r}_{\mathbf{2}}$ & $\mathbf{V}_{\mathbf{f}}$ & S.f \\
\hline & 1 & 0.5 & 0 & 20 \\
Variation $\mathrm{V}_{\mathrm{f}}$ & 2 & 0.5 & 0.5 & 20 \\
& 3 & 0.5 & 1 & 20 \\
& 4 & 0.5 & 1.5 & 20 \\
& 5 & 0.5 & 2 & 20 \\
\hline Variation & 6 & 0.5 & 2 & 20 \\
S.f & 7 & 0.5 & 2 & 15 \\
& 8 & 0.5 & 2 & 10 \\
\hline Variation & 9 & 0.25 & 2 & 20 \\
f/r $\mathrm{r}_{2}$ & 10 & 0.75 & 2 & 20 \\
\hline
\end{tabular}

10c Normal concrete shallow conical footing details with ring beam.

\begin{tabular}{ccccc}
\hline Group No. & Model No. & $\mathbf{f} / \mathbf{r}_{\mathbf{2}}$ & $\mathbf{V}_{\mathbf{f}}$ & S.f \\
\hline \multirow{3}{*}{ Change $\mathrm{f} / \mathrm{r}_{2}$} & 27 & 0.25 & 0 & 0 \\
& 28 & 0.50 & 0 & 0 \\
& 29 & 0.75 & 0 & 0 \\
\hline
\end{tabular}

Table 11 Physical properties for the tested sand.

\begin{tabular}{lc}
\hline \multicolumn{1}{c}{ Property } & Value \\
\hline \multicolumn{1}{c}{ Grain size analysis } \\
\hline Effective size, $\mathrm{D}_{10}$ & $0.26 \mathrm{~mm}$ \\
Coefficient of uniformity, $\mathrm{C}_{\mathrm{u}}$ & 2.38 \\
Coefficient of gradiation, $\mathrm{C}_{\mathrm{c}}$ & 0.99 \\
Classification (USCS) & \\
Specific gravity, $\mathrm{G}_{\mathrm{s}}$ & $\mathrm{SP}$ \\
\end{tabular}

\begin{tabular}{lc}
\hline \multicolumn{2}{c}{ Dry unit weights } \\
\hline Maximum dry unit weight, $\gamma_{\mathrm{d}(\max )}$ & $17.8 \mathrm{kN} / \mathrm{m}^{3}$ \\
Minimum dry unit weight, $\gamma_{\mathrm{d}(\min )}$ & $14.8 \mathrm{kN} / \mathrm{m}^{3}$ \\
\hline \multicolumn{1}{c}{ Void ratio } \\
\hline Maximum void ratio, $\mathrm{e}_{\max }$ & 0.73 \\
Minimum void ratio, $\mathrm{e}_{\min }$ & 0.44
\end{tabular}

* USCS refers to Unified Soil Classification System according to ASTM D 2487-2000.

could be produced by allowing the sand to fall as a rain to build up the required bed. It was found that factors which control the density are the intensity of the rain, i.e. the weight deposited. For a given intensity, an increase in height of fall increases the density.

Perforated plate rainer was used for controlling sand density. The configuration of this rainer consists of a square pan $(200 * 200 * 50) \mathrm{mm}$. The sand was rained through this perforated plate using different 10b RPC shallow conical footing without ring beam.

\begin{tabular}{lclll}
\hline Group No. & Model No. & $\mathbf{f} \mathbf{r}_{\mathbf{2}}$ & $\mathbf{V}_{\mathbf{f}}$ & S.f \\
\hline & 14 & 0.5 & 0 & 20 \\
\multirow{2}{*}{ Change $\mathrm{V}_{\mathrm{f}}$} & 15 & 0.5 & 0.5 & 20 \\
& 16 & 0.5 & 1.0 & 20 \\
& 17 & 0.5 & 1.5 & 20 \\
& 18 & 0.5 & 2.0 & 20 \\
\hline \multirow{2}{*}{ Change S.f } & 19 & 0.5 & 2.0 & 20 \\
& 20 & 0.5 & 2.0 & 15 \\
\multirow{2}{*}{ Change $\mathrm{f} / \mathrm{r}_{2}$} & 21 & 0.5 & 2.0 & 10 \\
& 22 & 0.25 & 2.0 & 20 \\
& 23 & 0.75 & 2.0 & 20 \\
\hline
\end{tabular}

10d Normal concrete shallow conical footing details without ring beam.

\begin{tabular}{ccccc}
\hline Group No. & Model No. & $\mathbf{f} / \mathbf{r}_{\mathbf{2}}$ & $\mathbf{V}_{\mathbf{f}}$ & $\mathbf{S . f}$ \\
\hline \multirow{3}{*}{ Change $\mathrm{f} / \mathrm{r}_{2}$} & 33 & 0.25 & 0 & 0 \\
& 34 & 0.50 & 0 & 0 \\
& 35 & 0.75 & 0 & 0 \\
\hline
\end{tabular}

heights of drop. Thus giving different values of placing density. The relation between height of drop and density of the sand in the locations of the calibrated cylinders is determined.

The direct shear test was performed to determine the consolidated-drained shear strength of a sandy to silty soil. From the plot of the shear stress versus the horizontal displacement, the maximum shear stress is obtained for a specific vertical confining stress. After the experiment is run several times for various vertical-confining stresses, a plot of the maximum shear stresses versus the vertical (normal) confining stresses for each of the tests is produced. The angle of internal friction, $\phi$, was found to be $36^{\circ}$.

\section{TESTING PROCEDURE}

All model tests are conducted using the setup which consists of rigid frame, soil tank, model conical footing and loading machine. The vertical load is applied to the model by means of 10 ton hydraulic compression handle jack. During all the experimental tests, the loading rate was kept approximately constant at $0.2 \mathrm{kN} / \mathrm{min}$. The applied load was measured using load cell 5 ton capacity. A digital weighing indicator was used to read and display the load value. Five deformation dial gages with $0.01 \mathrm{~mm}$ sensitivity have been used for measuring displacements of the model.

The soil tank has $1.0 \mathrm{~m}$ length, $1.0 \mathrm{~m}$ width, and $1.0 \mathrm{~m}$ height. It is supported by the frame. The dimensions of the tank were chosen so that the tank can be put inside the testing frame and there will be no interference between the walls of the soil tank and the failure zone around the foundation system. 
Table 12 Conical shell foundation failure loads.

\begin{tabular}{|c|c|c|c|}
\hline $\begin{array}{l}\text { Foundation } \\
\text { type }\end{array}$ & Foundation No. & $\begin{array}{c}\text { Failure load } \\
\text { (experimental) } \mathrm{kN}\end{array}$ & $\begin{array}{c}\text { Failure load based on soil } \\
\text { failure } \mathrm{kN} \text { (De Beer and } \\
\text { Vesid, 1958) }\end{array}$ \\
\hline \multirow{13}{*}{$\begin{array}{l}\text { With ring } \\
\text { beam }\end{array}$} & $\mathrm{S} 1\left(\mathrm{~V}_{\mathrm{f}}=0.0 \%\right)$ & 30 & 31 \\
\hline & $\mathrm{S} 2\left(\mathrm{~V}_{\mathrm{f}}=0.5 \%\right)$ & 30.5 & 32 \\
\hline & $\mathrm{S} 3\left(\mathrm{~V}_{\mathrm{f}}=1.0 \%\right)$ & 30 & 30.5 \\
\hline & $\mathrm{S} 4\left(\mathrm{~V}_{\mathrm{f}}=1.5 \%\right)$ & 31 & 32 \\
\hline & $\mathrm{S} 5\left(\mathrm{~V}_{\mathrm{f}}=2.0 \%\right)$ & 32 & 33.5 \\
\hline & S6 $(\mathrm{S} . \mathrm{f}=10 \%)$ & 30.4 & 31 \\
\hline & $\mathrm{S} 7(\mathrm{~S} . \mathrm{f}=15 \%)$ & 30 & 31 \\
\hline & S8 $(\mathrm{S} . \mathrm{f}=20 \%)$ & 29.5 & 31 \\
\hline & $S 9\left(\mathrm{f} / \mathrm{r}_{2}=0.25\right)$ & 28 & 29.3 \\
\hline & $\mathrm{S} 10\left(\mathrm{f} / \mathrm{r}_{2}=0.75\right)$ & 34 & 34.3 \\
\hline & $\mathrm{S} 11(\mathrm{e}=10 \mathrm{~mm})$ & 28 & 29.4 \\
\hline & $\mathrm{S} 12(\mathrm{e}=15 \mathrm{~mm})$ & 27 & 27.5 \\
\hline & $\mathrm{S} 13(\mathrm{e}=20 \mathrm{~mm})$ & 26 & 26.3 \\
\hline \multirow{13}{*}{$\begin{array}{c}\text { Without ring } \\
\text { beam }\end{array}$} & $\mathrm{S} 14\left(\mathrm{~V}_{\mathrm{f}}=0.0 \%\right)$ & 27 & 27.1 \\
\hline & $\mathrm{S} 15\left(\mathrm{~V}_{\mathrm{f}}=0.5 \%\right)$ & 27 & 27.8 \\
\hline & $\mathrm{S} 16\left(\mathrm{~V}_{\mathrm{f}}=1.0 \%\right)$ & 28 & 29 \\
\hline & $\mathrm{S} 17\left(\mathrm{~V}_{\mathrm{f}}=1.5 \%\right)$ & 28 & 28.5 \\
\hline & $\mathrm{S} 18\left(\mathrm{~V}_{\mathrm{f}}=2.0 \%\right)$ & 29 & 30 \\
\hline & $\mathrm{S} 19(\mathrm{~S} . \mathrm{f}=10 \%)$ & 26 & 27 \\
\hline & S20 (S.f $=15 \%)$ & 25.6 & 27 \\
\hline & S21 (S.f $=20 \%)$ & 25 & 26 \\
\hline & $\mathrm{S} 22\left(\mathrm{f} / \mathrm{r}_{2}=0.25\right)$ & 25.3 & 27 \\
\hline & $\mathrm{S} 23\left(\mathrm{f} / \mathrm{r}_{2}=0.75\right)$ & 30 & 31 \\
\hline & $\mathrm{S} 24(\mathrm{e}=10 \mathrm{~mm})$ & 24 & 26 \\
\hline & $\mathrm{S} 25(\mathrm{e}=15 \mathrm{~mm})$ & 23 & 24.5 \\
\hline & $\mathrm{S} 26(\mathrm{e}=20 \mathrm{~mm})$ & 21 & 21.9 \\
\hline
\end{tabular}

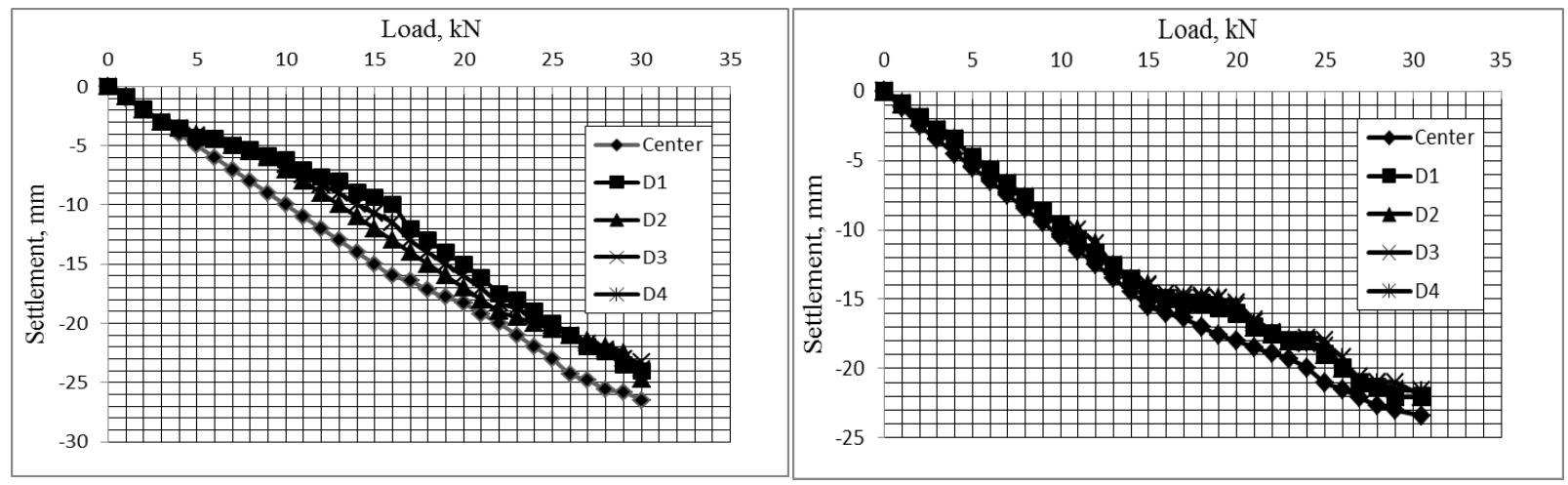

Fig. 2 Load - settlement relations for S model (1).

All foundations and control specimens were removed from water curing at the age of 28 days. Before the testing day, the foundations were cleaned and painted in order to clarify the crack propagation.

\section{RESULTS OF LOADING TESTS}

This section comprises of models S1, S2, S3, S4, and S5, given in Table 12. The models have identical dimensions of concrete and amount of reinforcement.
Fig. 3 Load - settlement relations for S model (2).

The measured values of deflections at the locations of the entire dial gauges are plotted against load, and shown in Figures 2 and 3. Similar figures are drawn for models 3, 4 and 5 .

It is noticed that the increase of the steel fibers $(0,0.5,1.0,1.5$, and 2.0$) \%$ leads to increase in the ultimate load of foundations compared to foundations without steel fibers by about 2, 4, 5, and $7 \%$, respectively. 


\section{THEORETICAL STUDY}

\subsection{THE ULTIMATE STRENGTH THEORY OF CONICAL SHELL FOUNDATION}

The procedure for design of the conical shell footings is essentially based on the membrane theory. A clear understanding of the behavior of the shell under different loading conditions is necessary for its design.

The membrane solution for the revolution in general, and for conical shell in particular, with the boundary conditions applicable to foundation, is available in standard works on shells. The membrane theory is based on equilibrium of stress alone. It is to be noted that membrane solutions are not available for any arbitrary loading and boundary conditions. In case, where membrane solutions are not possible for a particular loading and boundary conditions, the true picture of the state of internal stress in the shell can be obtained by the aid of the bending theory.

As footings for the columns or rafts of the tower shafts, the conical footing will not be the full cone, but the frustum of a cone (truncated cone). The radius of the top of the frustum of the conical foundation is therefore the same as the radius of the column or shaft, which the foundation supports (Roy and Kar, 1977).

A full conical shell, when fully filled, is subjected to uniform soil pressure with its direction either vertical or normal to the shell surface.

This is a case for which membrane solutions are available and used in design. The membrane normal and shearing stress results $\mathrm{N}_{\mathrm{s}}, \mathrm{N}_{\theta}$, and $\mathrm{N}_{\mathrm{s} \theta}$ developing in the shell due to the uniform symmetrical vertical or normal soil pressure, caused by a central by a central load, or a normal anti-symmetrical soil pressure caused by a moment, are given below (Roy and Kar, 1977).

\subsubsection{STRESS RESULTANTS UNDER SYMMETRICAL SOIL PRESSURE:}

Direction-vertical to the inside surface of cone, Figure (4a)

$N_{S}=-\frac{P_{v}}{2 S} \tan \alpha\left[S_{2}^{2}-S^{2}\right]$

$N_{\Theta}=P_{v} S \frac{\sin \alpha^{3}}{\cos \alpha}$

$N_{s \Theta}=0$

where,

$P_{v}=$ the intensity of vertical soil pressure,

$\mathrm{S}=$ distance of point on the conical shell from the vertex measured along the generator $(\mathrm{mm})$, and

$S_{2}=$ length of full the generator of cone $(\mathrm{mm})$.

$P_{v}=\frac{\text { Load }}{\text { Area }}=\frac{Q}{\pi r_{2}^{2}}$

\subsubsection{STRESS RESULTANTS UNDER SYMMETRICAL SOIL PRESSURE}

Direction-normal to the inside surface of cone, Figure (4a), the stresses are given in Appendix.

\subsubsection{STRESS RESULTANTS UNDER ANTI- SYMMETRICAL SOIL PRESSURE}

Direction-normal to the inside surface of cone as shown in Figure (4a) is given by Equations A5 to A8 in Apendix.

Variation of these stress resultants along the generator are shown in Figures (4 b and $4 \mathrm{c}$ ).

The membrane stress solution is an equilibrium solution. Generally, since the membrane stiffness of the shell is so large compared to its flexural stiffness, the latter mode does not become active in most cases. In the majority of cases, therefore, the estimation of stress based on the in-plane or membrane forces is to be deemed as adequate.

The ultimate strength of a foundation is the maximum load it can sustain under a given set of conditions. Ultimate strength analysis helps to estimate the load factors involved in the design. While ultimate strength analysis and design are well established in the case of plain structural elements, much work on ultimate analysis is lacking in the area of the shells, used either as roofs or foundations.

Generally, the analysis for the ultimate strength of the footing is based on the principle of virtual work.

Expressions have been developed which give the ultimate strength of conical shell footings subjected to central vertical loads, by kinematically analyzing failure mechanisms identified from the results of tests. What the expressions generally give are the ultimate values of the normal soil reactions, from the corresponding values of ultimate column loads can be readily calculated.

The ultimate uniform normal soil pressure, by assuming the footing to be fixed at top and free at bottom, and considering failure by circumferential (hoop) tension and radial bending, Figure 5, is provided by (Kurian, 2000) in Equation A9 in Appendix:

Several assumptions have been made to derive an expression for the ultimate soil pressure. The expressions coving the cases listed above apply to the following cases (Abd-Elmottaleb, 2005):

1. Hoop tension triangular, soil pressure uniform, and edge free.

2. Hoop tension constant, soil pressure uniform and edge with ring beam.

3. Hoop tension triangular, soil pressure triangular, and edge free.

4. Hoop tension constant, soil pressure triangular and edge with ring beam.

As an example, the expression pertaining to case (4) is given below:

The ultimate soil pressure (Abd-Elmottaleb, $2005)$ is given in Equation A10 in Appendix. 


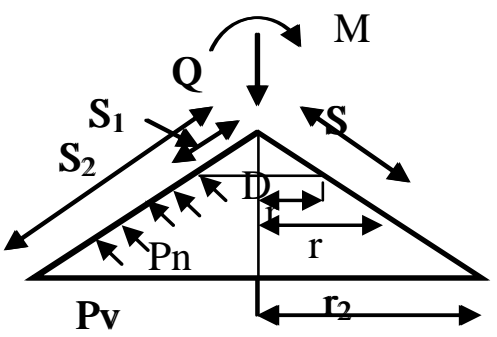

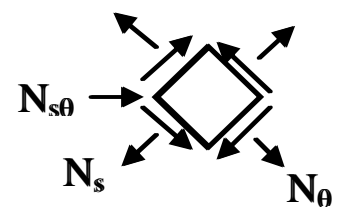

Shell element

Membrane stress resultants on shell element at $(\mathrm{s}, \theta)$

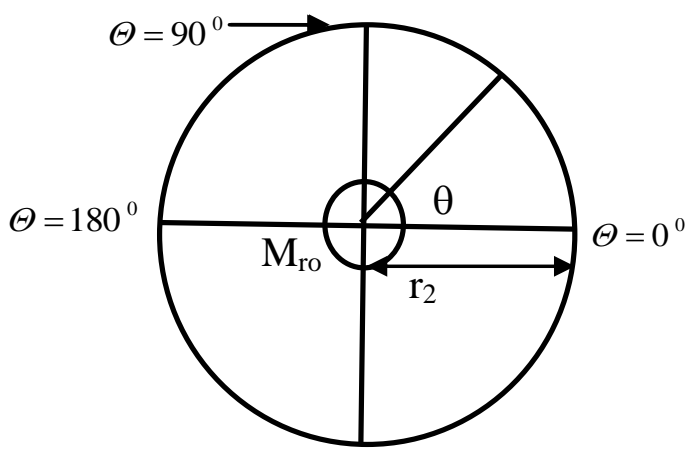

Direction of rotation

$\Theta=270^{\circ}$
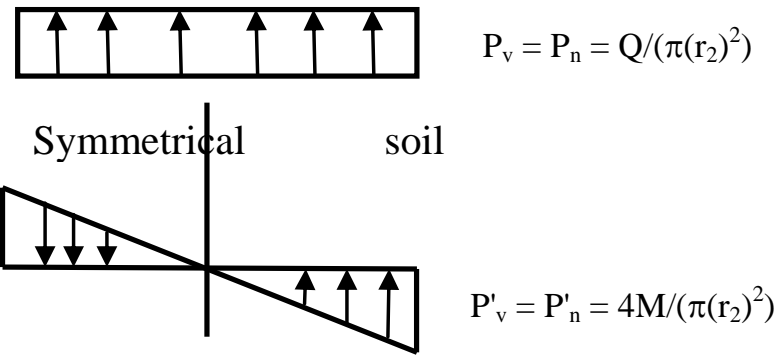

Anti-symmetrical soil

(a) General soil pressure under vertical load and moment.

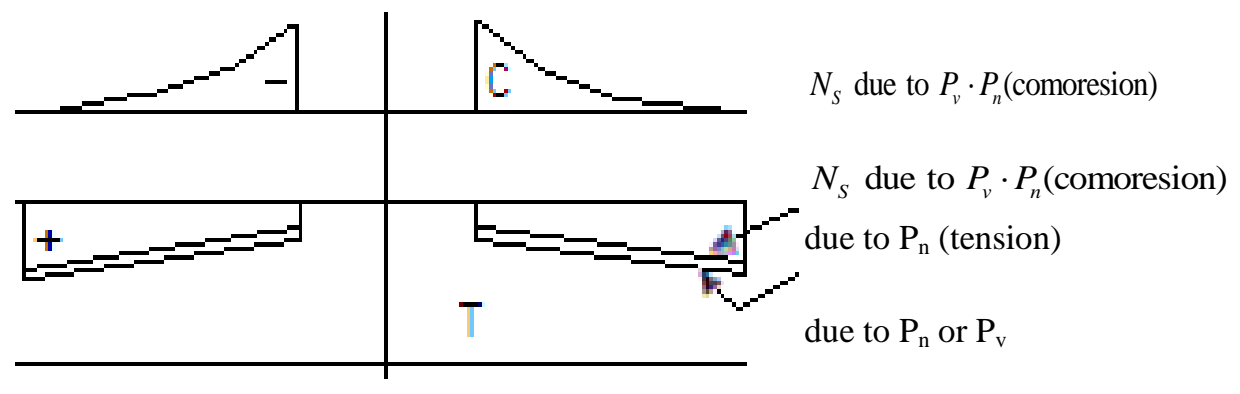

(b) Stress resultants due to symmetrical soil pressure.

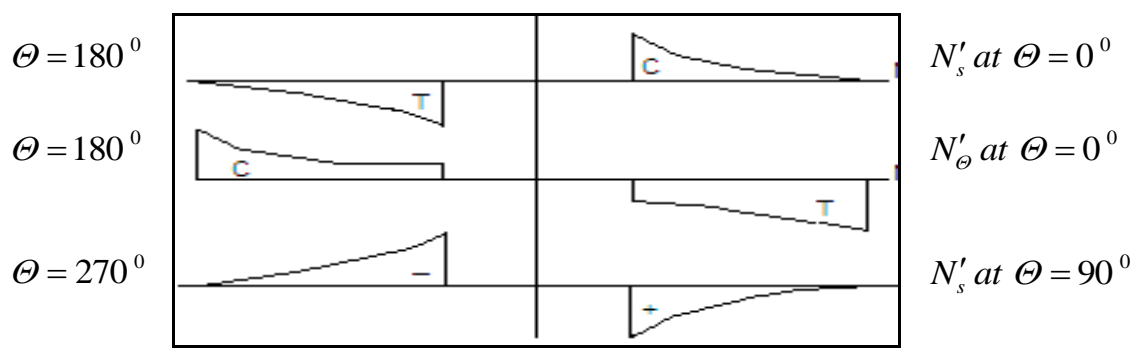

(c) Stress resultants due to anti-symmetrical soil pressure (normal soil pressure).

Fig. 4 Pressure distribution beneath conical shell footing (Roy and Kar, 1977). 


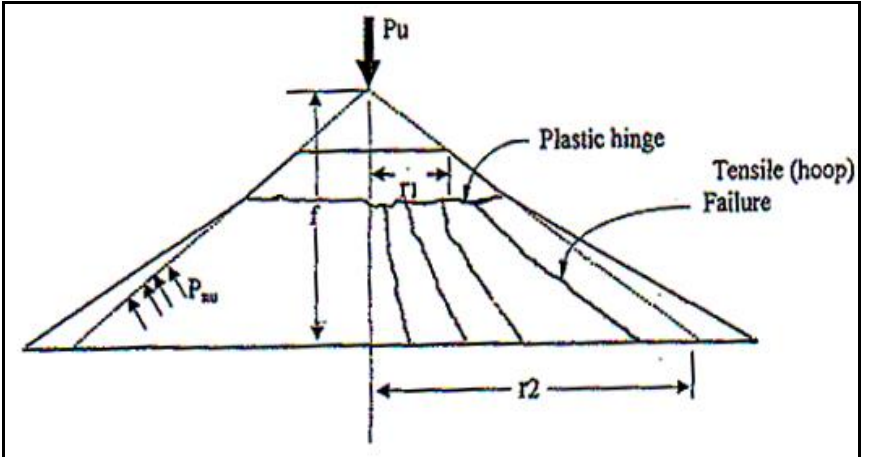

Fig. 5 Ultimate failure of conical footing (Kurian, 2004).

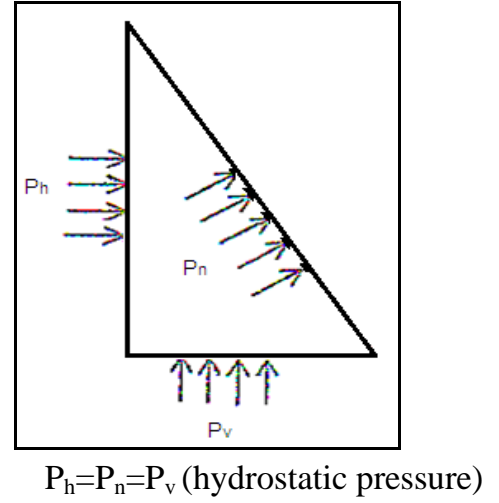

Fig. 6 Soil pressure on a shell foundation (Abd-Elmottaleb, 2005).
The ultimate column load (Abd-Elmottaleb, 2005) is given by Equation A11 in Appendix.

Kurian (2004) and Abd-Elmottaleb (2005) derived an expression for the ultimate strength (or column load at failure) of a conical shell footing subjected to a central vertical load and moment, as a function of eccentricity "e"=M/P.

They have derived their expression by considering:

1. The actual frustum of a cone in place of a full cone.

2. The resultant soil reaction is acting normal to the shell surface (the normal pressure at any point is composed of equal vertical and horizontal pressure of identical intensity as the normal) (Figure 6).

3. Footing designed for vertical load and moment considering the soil reaction to be normal.

4. A bottom ring beam of arbitrary design, which is redundant from the point of view of the membrane stress theory (Kurian, 2004; AbdElmottaleb, 2005).

The method of analysis that was followed is based on the yield line theory. The method essentially consists of the kinematic analysis of the mechanism of failure of these shell footings on models designed in accordance with membrane stress theory. This mechanism essentially consists of radial yield line across which the column base about which the radial strips rotates as shown in Figure 7 (Kurian, 2004; Abd-Elmottaleb, 2005).

They have got the expression for ultimate strength $\left(\mathrm{Q}_{\mathrm{un}}\right)$ as a function of eccentricity (Kurian, 2004; Abd-Elmottaleb, 2005) as given in Equation A12 in Appendix.

\subsection{PARAMETRIC STUDY ON THE ULTIMATE STRENGTH OF CONICAL SHELL FOUNDATIONS}

In the previous section, Equation A12 for the determination of the ultimate strength of the conical shell footings subject to vertical loads and moments were derived. This section deals with the studies conducted on the influence of parameters on the ultimate strength of the conical shell footings. The parameters so chosen are the followings:

1. Rise of the shell.

2. Eccentricity of the applied load.

The parametric study has been facilitated by programming the complicate (or rather complex) expressions of the final Equation (A12) given for $\mathrm{Q}_{\mathrm{u}}$.

In the parametric study, it is necessary to use data relating to a specific footing. In this connection, it was thought expedient to use the data pertaining to the models of the conical shell footings tested and reported in this work.

In this study, the influence of one parameter at a time is considered; the other parameters of the problem are kept constant. As mentioned above, the following general data apply to the model unless specified otherwise;

$$
\mathrm{r}_{2}=180 \mathrm{~mm} \quad \mathrm{r}_{1}=30 \mathrm{~mm} \quad \mathrm{f} / \mathrm{r}_{2}=1 / 2
$$

Shell thickness $=10 \mathrm{~mm}$

Reinforcement- $\phi 2 \mathrm{~mm}$ diameter mild steel wire yield strength of $310 \mathrm{~N} / \mathrm{mm}^{2}$.

\subsection{ULTIMATE STRENGTH $Q_{U}$ WITH $f / r_{2}$ WITHOUT RING BEAM}

The rise to base radius ratio $\left(\mathrm{f} / \mathrm{r}_{2}\right)$ of the footing is taken as the cotangent of the vertical semi-angle $\alpha$

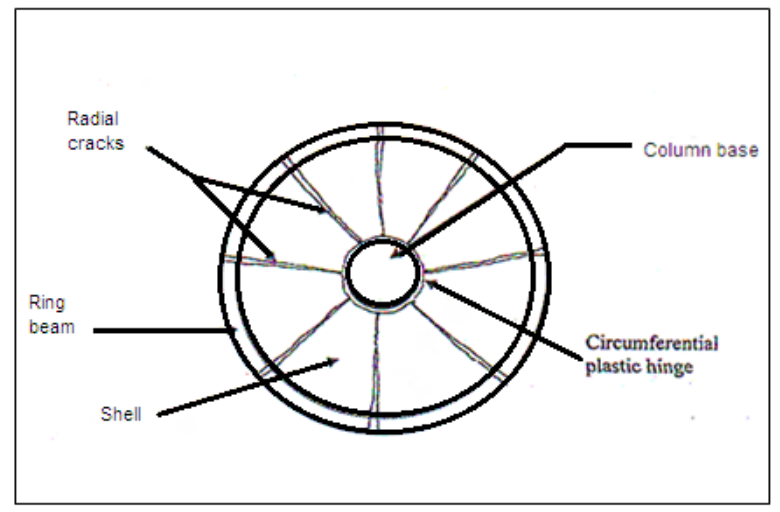

Fig. 7 Mode of failure of conical footing (Kurian, 2004, Abd-Elmottaleb, 2005). 


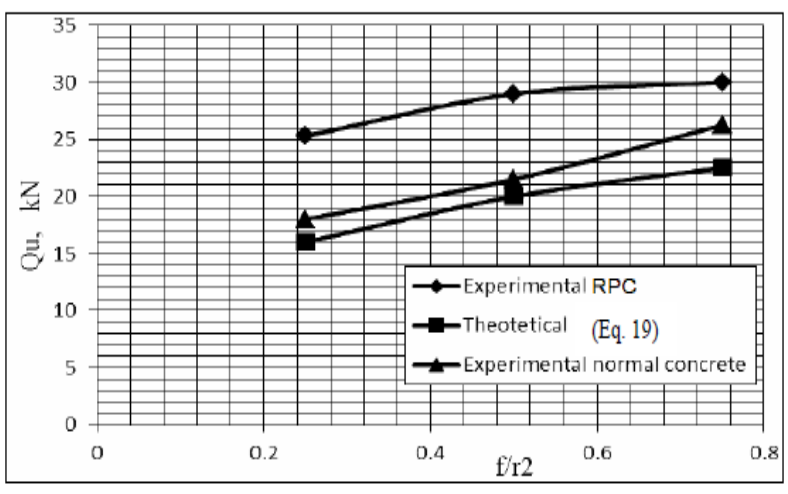

Fig. 8 Variation of $Q_{u}$ with $f / r_{2}$ in shell foundation without ring beam.

of the footing and appears in the expression of Equation A12. It is proposed to study the influence of the parameter $f / r_{2}$, in other word $\alpha$, the geometry of the footing varies with the rise (i.e. $\alpha$ ), but the sections of the footing remain constant.

Kurian (2004) and Abd-Elmottaleb (2005) derived their theoretical expression (Equation A12). Through their expression, they have designed a tensile capacity of shell section due to steel provided for $N_{\theta}$ given as $\mathrm{n}_{\theta}$ :

$n_{\Theta}=N_{\Theta} \frac{\sigma_{s y}}{\sigma_{s t}}$

where:

$\sigma_{s t}$ is the permissible tensile stress in steel, and $\sigma_{s y}$ is the yield strength.

The hoop tension capacity is given in Equation A6 (Kurian, 2004, Abd-Elmottaleb, 2005):

Hence, the final expression for a centrally loaded conical shell footing without a ring beam will be (Kurian, 2004 and Abd-Elmottaleb, 2005) is given in Equation A13 in Appendix.

Using the expression of Equation A13, the variation of $Q_{u}$ with $f / r_{2}$ is studied. Figure 8 shows the theoretical and experimental variations of $Q_{u}$ with $\mathrm{f} / \mathrm{r}_{2}$. The figure shows an initial increase in the theoretical value of $Q_{u}$ then followed by a relatively slower increase starting at the limited value of $\mathrm{f} / \mathrm{r}_{2}=1$ as suggested in the Indian Code (IS, 2008). However, the experimental variation of $Q_{u}$ fast increases with $\mathrm{f} / \mathrm{r}_{2}$, while the hoop tensile stresses decrease. Figure 8 shows that a comparison between the theoretical values which are based on normal concrete with experimental results on both normal concrete and RPC. The value of $Q_{u}$ increase when using RPC by about $44.1 \%$ from normal concrete.

\subsection{ULTIMATE STRENGTH $Q_{u}$ WITH $f / r_{2}$ WITH RING BEAM}

The variation of $Q_{u}$ with $\mathrm{f} / \mathrm{r}_{2}$ when the conical shell foundation is provided in the ring beam is

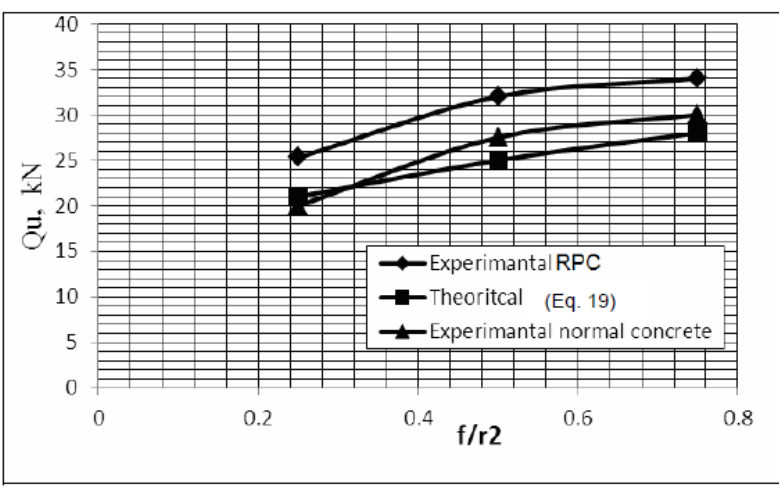

Fig. 9 Variation of $Q_{u}$ with $f / r_{2}$ in shell foundation with ring.

studied. Using Equation A7, the variation of $Q_{u}$ with $\mathrm{f} / \mathrm{r}_{2}$ has been studied for a conical shell footing, using three different cases of $\mathrm{f} / \mathrm{r}_{2}$ provided as in the experimental work. Results of the theoretical and experimental $Q_{u}$ with respect to $\mathrm{f} / \mathrm{r}_{2}$ are shown in Figure 9. It can be shown that the values of $Q_{u}$ increase when using RPC by about $25.2 \%$ compared with $Q_{u}$ based on using normal concrete.

\subsection{ULTIMATE STRENGTH $Q_{u}$ WITH ECCENTRICITY (e)}

In the parametric study on eccentricity, it is prospered to discuss the variation of the ultimate strength $Q_{u}$ with the eccentricity of load of a conical footing which is designed for a specific value of eccentricity $\left(e_{d}\right)$. Irrespective of the variation of e, the capacities of sections remain the same. Hence, $P_{n}$ appearing as substituted by Equation A14 in Appendix.

Variation of $Q_{u}$ with respect to e has been studied for three cases of rise to base radius ratio of the conical shell footing. The studies were conducted for cases of with and without bottom ring beams. Under the above cases, data pertaining to the design of models under a central loading $\left(\mathrm{e}_{\mathrm{d}}=0\right)$ and three specific eccentricities (same a in the experimental work, $\mathrm{e}_{\mathrm{d}}=10 \mathrm{~mm}, 15 \mathrm{~mm}$, and $20 \mathrm{~mm}$ ) were taken as input and the results were obtained.

Variation of $Q_{u}$ with e obtained in this study is shown in Figure 10. This figure shows the variation of $Q_{u}$ of models designed originally for eccentricity of $10 \mathrm{~mm}, 15 \mathrm{~mm}$, and $20 \mathrm{~mm}$ and for a central load, when subjected to different eccentricities of applied loading

Figure 11 shows the interesting result that three is an initially slight increase of ultimate load with eccentricity but followed by a rapid decrease. This reveals that the conical shell footing can admirably resist smaller values of accidental eccentricities of load (due to unanticipated moment) that may occur in practice. From Figures 10 and 11, the ultimate load of conical shell foundation with ring beam increases 


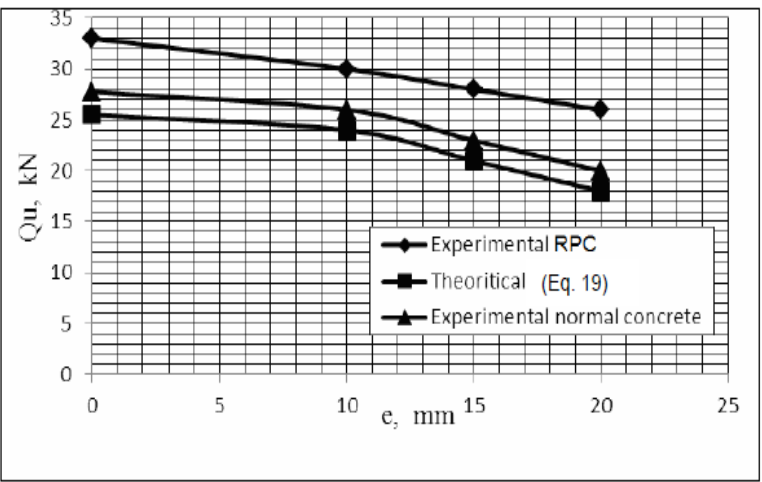

Fig. 10 Variation of $Q_{u}$ with $e$ in conical shell foundation with ring beam.

when using RPC by about $32.9 \%$ compared to normal concrete and the ultimate load of conical shell foundation without ring beam increases by about $10.5 \%$ from normal concrete respectively.

\section{CONCLUSIONS}

1. The inclusion of steel fibers in RPC footings results in enhanced stiffness, reduced crack width and reduced rate of crack propagation. At failure, the RPC footings behave in a ductile manner as compared with the non fibrous footing and most of the steel fibers pulled out of the cement matrix.

2. The parametric study and results of tests show that the conical shell foundations are admirably suited to resist small eccentricities of applied load that are bound to occur in practice.

3. It should be appreciated that this approach is sufficiently sound so long as the core soil can be assumed to behave integrally with the footing. An interesting side effect of this is that, there is a great friction available between the core soil and the foundation soil in the case of shell footings, to resist horizontal loads.

4. The increased ratio of height to radius $\left(\mathrm{f} / \mathrm{r}_{2}\right)$ for the shell foundation from 0.25 to 0.75 increases the ultimate load of footing by about $15 \%$.

5. The conical shell footing can admirably resist smaller values of accidental eccentricities of load (due to unanticipated moment) that may occur in practice.

\section{REFERENCES}

Abd-Elmottaleb, H. E.: 2005, Nonlinear modeling of R.C. buildings including foundation-soil interaction. Ph.D. Thesis, Structural Eng. Dept. Zagazig University, Egypt.

ASTM A615/615M-05a: 2005, Standard specification for deformed and plain carbon structural steel bars for concrete reinforcement. Annual Book of ASTM Standards, 01.02, American Society for Testing and Materials.

ASTM C109/C109M-2005: 2005, Standard test method for compressive strength of hydraulic cement mortars.

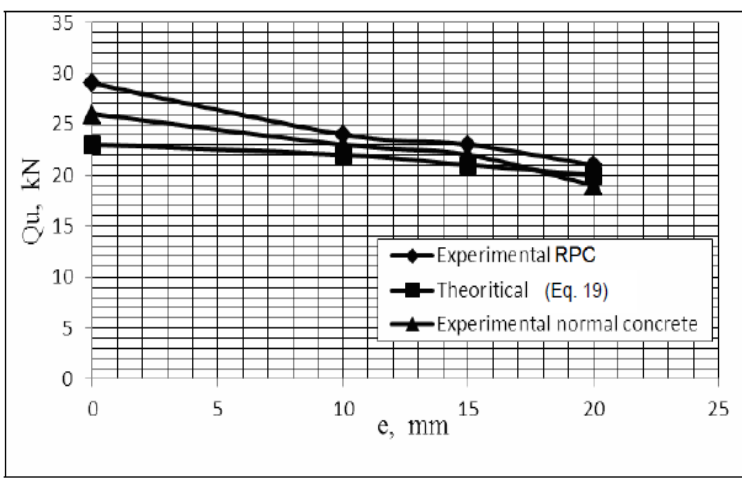

Fig. 11 Variation of $\mathrm{Q}_{\mathrm{u}}$ with $\mathrm{e}$ in conical shell foundation without ring beam.

American Society for Testing and Materials, 04.01, 6 pp.

ASTM C39/C39M-05: 2003, Standard test method for compressive strength of cylindrical test specimen. American Society for Testing and Materials, 04.02, 67 pp.

ASTM C1437-2001: 1999, Standard test method for flow of hydraulic cement pastes and mortars of plastic consistency. American Society for Testing and Materiále; 04.01, 3 pp.

ASTM C230 / C230M - 14: Standard Specification for Flow Table for Use in Tests of Hydraulic Cement", American Society for Testing and Materials.

ASTM D2487: 2000, Standard Test Method for ParticleSize Analysis of Soils. 02.01,

B.S. 882/1992: 1992, Specification for Aggregates from Natural Sources for Concrete. British Standard Institution, $5 \mathrm{pp}$.

De Beer, E.E. and Vesid, A.: 1958, Etude experimental de la capacity portent due sable sours des foundations directs eatables en surface. Annales des Travaux Publics de Beiqique, 59, No. 3, 5-58.

Esmaili, D. and Hataf, N.: 2008, Experimental and numerical invetigation of ultimate load capacity of shell foundations on reinforced and unreinforced sand. Iranian Journal of Science \& Technology, Transaction B, Engineering, 32, No. B5, 491-500.

Huat, B.B.K. and Mohammed, T.A.: 2006, Finite element study using FE Code (PLAXIS) on the geotechnical behavior of shell footings. Journal of Computer Science, 2 (1), 104-108.

Indian Standard Code of Praktice: 1980,. Design and Construction of Conical and Hyperbolic Paraboloidal Types of Shell Foundations.

Kurian, N.P.: 1982, Modern Foundations: Introduction to Advanced Techniques. Tata - McGraw Hill, New Delhi.

Kurian, N.P.: 2000, Shell foundations-The Asian Choice. New Building Materials and Construction World.

Kurian, N.P.: 2004, Shell foundations-rationale and use. International Conference on Modern Trends in Foundation Engineering: Geotechnical Challenges Solutions, 21-26 January, Organized by Geotechnical Engineering Division, Department of Civil Engineering, Indian Institute of Technology, Madras, Chennai- 600036, India, 1-18. 
Kurien, N.P.: 2006, Shell Foundation. Narosa Publishing House, New Delhi.

Philippot, S., Masse, S., Zanni, H., Nieto, P., Maret, V. and Cheyrezy, M.: 1996, Study of hydration and pozzolanic reactions in reactive powder concrete (RPC). Magnetic Resonance Imaging, 114, No. 8, 891-893. DOI: 10.1016/S0730-725X(96)00174-9

Ramaswami, G.S. and Rafik, N.: 1972, Load Test on a Model Hyperbolic Paraboloid Footing. Research Paper RP. 14 / 72, Building Research Center, Baghdad, Iraq.

Roy, S. and Kar, P.: 1977, On conical and spherical shell foundations. Journal of Structural Engineering (Roorkee), 4. No. 4, 137-142.
Saderkarimi, A.: 2004, Development of a lightweight reactive powder concrete. Journal of Advanced Concrete Technology, 2, No. 3, 409-417.

Sika Gulf B.S.S.C., (2006) Sika ${ }^{\circledR}$ ViscoCrete ${ }^{\circledR}-3110$ Concrete Admixture for High Slow/Self Compacting Concrete, Sika data sheet, Edition 1/06.

Silica Fume User's Manual: 2005, Federal Highway Administration.

Sharma, A.K. and Mawal, M.B.: 1971, A new foundation for tower-shaped structures. Indian Geotechnical Journal, New Delhi, 1, No. 2, 172-184.

\section{APPENDIX}

\section{EQUATIONS FOR THEORETICAL APPROACH}

$$
\begin{aligned}
& N_{s}=-\frac{P_{n}}{2 S} \tan \alpha\left[S_{2}^{2}-S^{2}\right] \\
& N_{\Theta}=P_{n} S \tan \alpha \\
& N_{s \Theta}=0
\end{aligned}
$$

where, $P_{n}$ is the intensity of normal soil pressure on the inside surface of cone.

$$
P_{n}=\mathrm{Load} / \text { Area }=Q / \pi r_{2}^{2}
$$

Since

$$
\mathrm{S}=\mathrm{r} / \mathrm{sin} \alpha
$$

$$
\mathrm{N}_{\theta}\left(\mathrm{P}_{\mathrm{n}} \times \mathrm{r}\right) / \cos \alpha
$$

The angle $\alpha$ can be taken as a design angle $\alpha_{\mathrm{d}}$,

$$
\begin{aligned}
& N_{s}^{\prime}=-\frac{2 P_{n}^{\prime}}{S_{2} \sin 2 a} 3\left[\frac{S_{2}^{4}-S^{4}}{4 S^{2}}-\frac{S_{2}^{3}-S^{3}}{4 S} \cos \Theta^{2}\right] \cos \Theta \\
& N_{\Theta}^{\prime}=\frac{P_{n}^{\prime} S^{2}}{\check{S}_{2}} \tan \alpha \cos \Theta \\
& N_{s \Theta}^{\prime}=\frac{P_{n}^{\prime}\left(S_{2}^{4}-S^{4}\right)}{4 S_{2} S^{2} \cos a} \sin \Theta
\end{aligned}
$$

in which

$$
\begin{aligned}
& P_{n}^{\prime}=\frac{4 Q e}{\pi S_{2}^{3} \sin \alpha^{3}}=\frac{4 Q e}{\pi r_{2}^{3}}=\frac{4 M}{\pi r_{2}^{3}} \\
& \text { Pnu }=6\left[\frac{\left.\frac{\frac{\cos \alpha}{2}\left(1-R_{0}\right)^{2}+\frac{M \sin \alpha^{2}}{N r_{2}} R_{0}}{R_{0}^{3}-3 R_{0}+2}\right] \frac{N}{r_{2}}}{}\right.
\end{aligned}
$$

in which

$$
R_{0}=\frac{r_{0}}{r_{2}}
$$


where :

$r_{o}=$ the radius corresponding to the location of the plastic hinge Figure 5 ( $r_{o}$ may be taken as $r_{l}$ for all practical purposes),

$r_{2}=$ the radius at base,

$P n u=$ The ultimate uniform normal soil pressure,

$N=$ ultimate capacity of the shell section per unit width in direct tension in the hoop direction (constant), and $M=$ moment capacity of the plastic hinge per unit width.

$$
P_{n_{u}}=\frac{12}{\left(1-2 R_{0}-2 R_{0}^{3}-R_{0}^{4}\right)}\left[\frac{N \cos \alpha\left(1-R_{0}\right)^{2}}{2 r_{2}}+\frac{M \sin \alpha^{2} R_{0}}{r_{2}^{2}}+\frac{N_{b}\left(1-R_{0}\right) \sin \alpha \cos \alpha}{r_{2}^{2}}\right]
$$

where:

$P_{n u}=$ The ultimate uniform normal soil pressure,

$N_{\mathrm{b}}=$ the ultimate tensile capacity of the section of the ring beam, and

$R_{0}=\frac{r_{0}}{r_{2}}$, where $\mathrm{r}_{\mathrm{o}}$ is the radius corresponding to the location of the plastic hinge (Figure 5) ( $\mathrm{r}_{\mathrm{o}}$ may be taken as $\mathrm{r}_{1}$ for all practical purposes), and $r_{2}$, the radius at base.

$Q_{u}=P_{n_{u}} \times A_{p}=P_{n_{u}}\left[\frac{\pi r_{2}^{2}}{3}\left(2 R_{1}^{3}-3 R_{1}^{3}+1\right)\right]$

where:

$Q_{u}=$ The ultimate column load.

$P_{n u}=$ The ultimate uniform normal soil pressure, and

$R_{1}=\frac{r_{1}}{r_{2}}, \mathrm{r}_{1}$ is the top radius of truncated cone.

$A_{p}=$ area under shell.

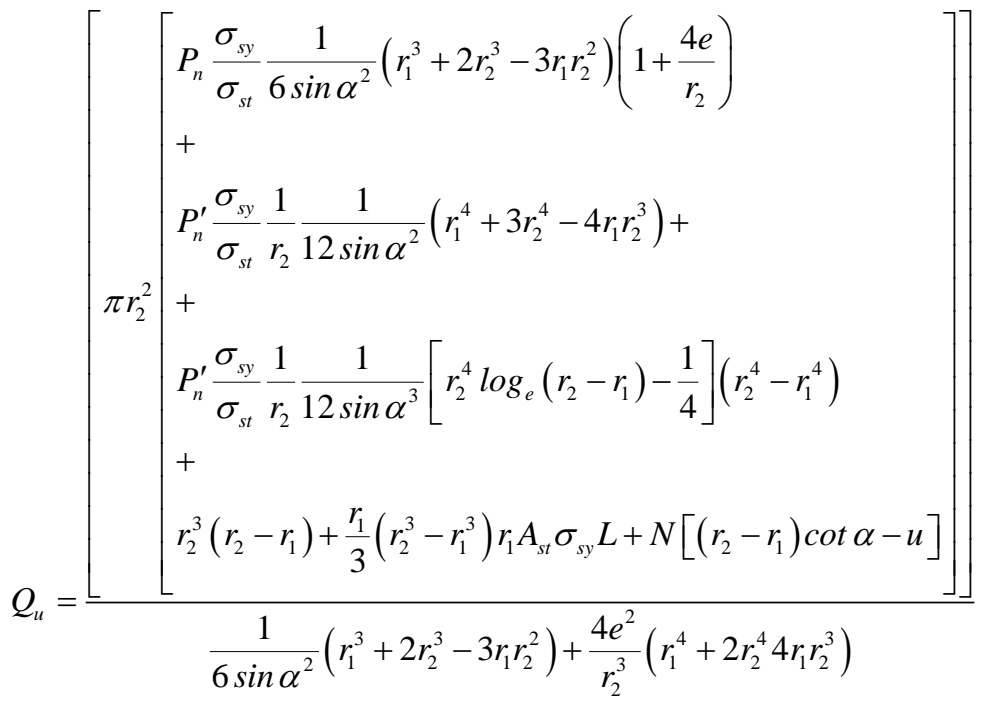

The above being the most general case, expressions pertaining to simpler case can be obtained by using suitable assumptions.

$Q_{u}=\frac{\left[\pi r_{2}^{2}\left[\frac{P_{n}}{\cos \alpha d} \frac{\sigma_{s y}}{\sigma_{s t}} \frac{\cos \alpha}{6 \sin \alpha^{2}}\left(r_{1}^{3}+2 r_{2}^{3}-3 r_{2}^{2}\right)+r_{1} A_{s t} \sigma_{s y} L\right]\right]}{\left[\frac{1}{6}\left(r_{1}^{3}+2 r_{2}^{3}-3 r_{1} r_{2}^{2}\right)\right]}$

$P_{n}=\frac{4 Q e_{d}}{\pi r_{2}^{3}}$ 
where $Q$ is the design load at the design eccentricity of $\mathrm{e}_{\mathrm{d}}$. However, the work done by the soil pressure depends on the eccentricity parameter e. Thus the expression for the ultimate load $Q_{u}$ used in the parametric study pertaining to e takes the form (Kurian (2004) and Huat et al. (2006)):

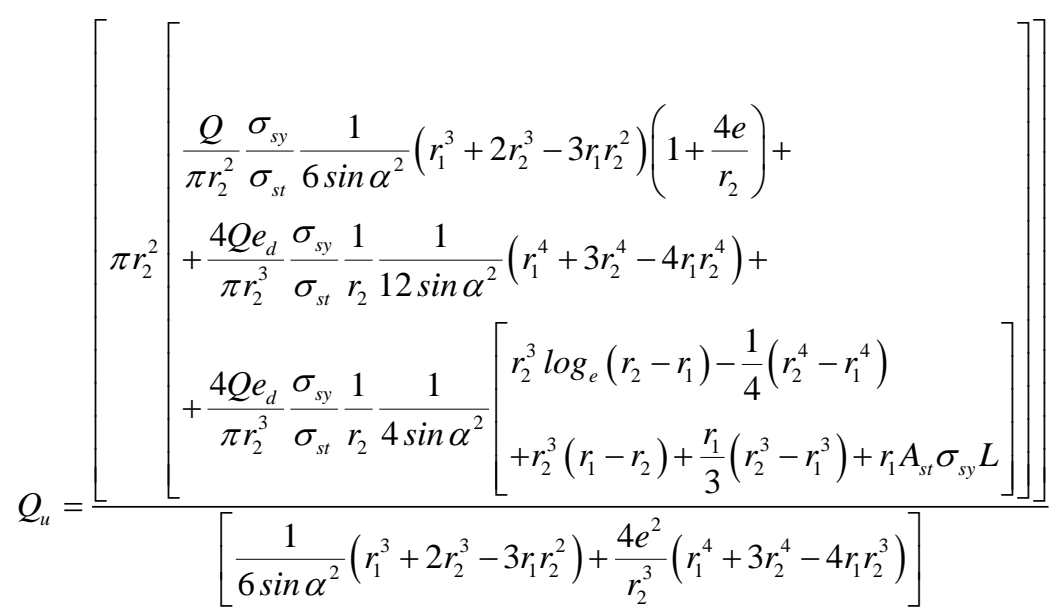

